Article

\title{
Polystyrene Nanoplastic Behavior and Toxicity on Crustacean Daphnia magna: Media Composition, Size, and Surface Charge Effects
}

\author{
Alexis Pochelon, Serge Stoll *(i) and Vera I. Slaveykova *(i) \\ Department F.-A. Forel for Environmental and Aquatic Sciences and Institute for Environmental Sciences, \\ School of Earth and Environmental Sciences, Faculty of Sciences, University of Geneva (Uni Carl Vogt), \\ CH-1211 Geneva, Switzerland; alexis.pochelon@asleman.org \\ * Correspondence: serge.stoll@unige.ch (S.S.); vera.slaveykova@unige.ch (V.I.S.)
}

check for updates

Citation: Pochelon, A.; Stoll, S.; Slaveykova, V.I. Polystyrene Nanoplastic Behavior and Toxicity on Crustacean Daphnia magna: Media Composition, Size, and Surface Charge Effects. Environments 2021, 8, 101. https://doi.org/10.3390/ environments 8100101

Academic Editors: Teresa A. P. Rocha-Santos and Joana C. Prata

\section{Received: 8 July 2021}

Accepted: 22 September 2021

Published: 28 September 2021

Publisher's Note: MDPI stays neutral with regard to jurisdictional claims in published maps and institutional affiliations.

Copyright: (C) 2021 by the authors Licensee MDPI, Basel, Switzerland. This article is an open access article distributed under the terms and conditions of the Creative Commons Attribution (CC BY) license (https:/ / creativecommons.org/licenses/by/ $4.0 /)$.

\begin{abstract}
Concerns about the possible ecotoxicological implications of nano-sized plastic materials in the freshwater environment are growing with the increasing use of plastic materials. The present study focuses on the behavior and effects of amidine-functionalized polystyrene (NPLs) of 20, 40, 60, and 100-nm-size in freshwaters and different synthetic media. Daphnia magna was exposed to increasing concentrations from 0.5 to $30 \mathrm{mg} / \mathrm{L}$ (and from 0.5 to $100 \mathrm{mg} / \mathrm{L}$ for 100-nm-sized NPLs). The results revealed no significant aggregation in ultra-pure water, culture media, and synthetic water. In the presence of natural organic matter, NPLs of 20 and $40 \mathrm{~nm}$ displayed better stability in both freshwater and synthetic media, whereas a significant aggregation of 60 and $100 \mathrm{~nm}$ PS NPLs was found. All the studied PS NPLs with size between 20 and $100 \mathrm{~nm}$ exhibited acute toxicity to D. magna. The observed 48-h immobilization strongly depended on the primary size of PS NPLs, with 20 and 40-nm-size PS NPLs inducing a stronger effect in both freshwaters and synthetic media. Water quality variables such as $\mathrm{pH}$, cation and anion composition, and DOC were of secondary importance. The results of the present study confirmed the toxicity of NPLs of different sizes to crustaceans in natural freshwater and synthetic media and demonstrated the importance of the primary size of NPLs in the behavior and effects of NPLs.
\end{abstract}

Keywords: nanoplastics; freshwaters; synthetic media; stability; eco-corona; ecotoxicity; surface charge; Geneva Lake; D. magna

\section{Introduction}

The abundance of nano-sized plastic materials in the aquatic environment is continuously increasing with the increasing use of plastic materials and their environmental degradation via physical, chemical, and biological processes [1-3]. Concerns about their possible ecotoxicological implications are increasing [4,5]. Hence, the comprehensive understanding of their behavior, bioaccumulation, and toxicity potential is highly sought. Indeed, important advancements in the knowledge of the fate and impact of nano-sized plastics in marine systems have been already achieved, as recently reviewed [6,7]. However, similar studies dealing with freshwater ecosystems are rather limited $[1,4,5,8,9]$, despite the fact that freshwaters such as lakes are considered to be highly heterogeneous sinks of plastics.

In aquatic systems, nano-sized plastics or nanoplastics (NPLs) will undergo a variety of transformations due to the presence of natural organic matter (NOM) and inorganic colloids (ICs) that will influence their ultimate fate $[10,11]$. In particular, they will rapidly and inevitably interact with different components of NOM, such as humic substances and extracellular polymeric substances (EPS) [1,6,11-13], resulting in the formation of an eco-corona (or environmental corona) that will modulate NPLs' bioreactivity and potential impacts $[11,14,15]$. Such interactions will be modulated by the medium properties $(\mathrm{pH}$, 
ionic composition, presence of divalent cations, temperature), NOM properties such as hydrophobicity [14], the presence of functional charged groups, ICs and NPLs' intrinsic properties (size, surface charge, density), and the concentration ratio between NOM, ICs, and NPLs. Such interactions will control NPLs' behavior and stability, in particular regarding surface coating and charge, and heteroaggregate formation with NOM and ICs. Such processes will control their environmental transport and fate by controlling, for example, their sedimentation or floating behavior (Nasser et al. 2020), distribution, and transport in the water column and interactions with aquatic biota.

The existing literature on the toxic effect of different micro- and nano-sized plastic materials towards freshwater organisms was recently reviewed [4,5,16-18], evidencing both acute and chronic effects in algae, ciliates, crustaceans, and fish. For the cladoceran Daphnia magna, used as a freshwater zooplankton model in the present work, both acute and chronic effects were found upon exposure to NPLs of different size and surface functionalization [14,16,19-27]. For example, $0.40 \mathrm{mg} / \mathrm{L}$ to $416.5 \mathrm{mg} / \mathrm{L}$ polyethyleneamine polystyrene (PS) of 55 and 110-nm-size induced 48-h immobilization of D. magna [21], as well as poly $N$-isopropylacrylamide and $N$-isopropylacrylamide/ $N$-tert-butylacrylamide copolymer nanoparticles of 50-70 nm [22]. A toxic effect in D. magna was observed for methylmethacrylate-based NPLs in concentrations between 500 and $1000 \mathrm{mg} / \mathrm{L}$ [20]. Protein-coated $88 \mathrm{~nm} \mathrm{NH}_{2}{ }^{-}$and COOH-PS were found to be more toxic to D. magna than the uncoated ones [23]. Reduced body size, a severe alteration in reproduction, and the appearance of malformations in neonates were observed upon exposure to 70-nmsize pristine, aged, and aged filtered polystyrene NPLs tested in the concentration range between $0.22 \mathrm{mg} / \mathrm{L}$ and $103 \mathrm{mg} / \mathrm{L}$ [19]. Prolonged exposure to $100 \mathrm{~nm}$ PS NPLs was also shown to decrease D. magna feeding rates [24]. An exposure to $1 \mathrm{mg} / \mathrm{L}$ of $71 \mathrm{~nm}$ PS for $96 \mathrm{~h}$ resulted in oxidative stress, the alteration of the immune defense, and glycol metabolism change in Daphnia pulex, as recently revealed by transcriptomic profiling [27]. Similarly, $\mathrm{NH}_{2}$-PS (exposure range $50-100 \mathrm{mg} / \mathrm{L}$ ) induced an upregulation of various genes involved in detoxification, oxidative stress, and endocrine activity after $24 \mathrm{~h}$ exposure in D. magna [14]. The presence of NOM and humic acids resulted in the mitigation of gene expression as well as the alleviation of acute toxicity; however, the presence of fulvic acid intensified the gene expression and favored protein adsorption on NPLs in the culture medium and D. magna homogenates [14]. Amidine PS NPLs with a size of $200 \mathrm{~nm}$ were found to be more toxic than carboxyl ones; the addition of alginate or humic acid led to the formation of eco-corona on amidine PS nanospheres and reduced their toxicity, but this eco-corona was found to have a minor effect on the carboxyl PS [28]. The comparison of the effect of PS NPLs with different functionalization (plain, negatively and positively charged amine- and carboxylate-modified PS) revealed the highest acute toxicity of plain PS, while the functionalized PS NPLs were less toxic [25]. The presence of humic acid reduced the acute toxicity of these PS NPLs with different functional groups and charges to D. magna [29]. However, despite recent progress, systematic studies on the role of nano-sized plastics and their behavior and possible effects in freshwaters are still missing, despite the fact that they are recognized as central for their ecological and ecotoxicological outcome [3-6,18].

The aim of the present study is to improve the understanding on the behavior of NPLs in lake ecosystems and different media, and assess their potential effects on aquatic crustacean D. magna under more realistic conditions. The specific emphasis was on: (i) examining the role of the primary size of NPLs in their stability and acute effects on water flea D. magna, as representative of freshwater crustaceans; (ii) deciphering the influence of NOM and other water quality variables on the NPLs' fate, such as aggregation and surface charge modifications via eco-corona formation, and the effect on zooplankton. 


\section{Materials and Methods}

\subsection{Experimental Design, Choice of NPLs, Natural Freshwaters, and Synthetic Media}

To examine the effect of the primary particle size on the behavior of NPLs in different media, amidine $\left(-\mathrm{CNH}_{2} \mathrm{NH}_{2}{ }^{+}\right)$derivatized hydrophobic polystyrene (PS) nanospheres, charge-stabilized, with primary diameters of 20, 40, 60, and $100 \mathrm{~nm}$ were used as model NPLs. Polystyrene nanospheres were chosen since polystyrene is one of the most widely used types of plastics [2,30]. In particular, amidine-functionalized nanoparticles were chosen as they are usually positively charged in a large $\mathrm{pH}$ range (from 4 to 10), which makes the interaction with microorganisms easier, which are, by default, negatively charged [31]. Surfactant-free aqueous suspensions $(4 \% w / v)$ were purchased from Invitrogen (Thermo fisher scientific, Waltham, MA, USA). Characteristics of these NPLs are provided in Table S1. Suspensions prepared in ultra-pure water (UPW) were quite homogeneous, with welldefined size distributions and uniform spherical shape, as shown by SEM and image analysis (Figures S1 and S2). The concentration of the styrene mono and oligomers released by the NPLs [32] in the tested media was considered negligible. Polystyrene NPLs' density $\left(1.055 \mathrm{~g} / \mathrm{cm}^{3}\right.$ at $\left.20^{\circ} \mathrm{C}\right)$ was comparable with the density of freshwaters, which classifies them as neutrally buoyant.

To explore the role of media composition on PS NPLs' stability and toxicity, freshwater was sampled at different locations of a natural reserve marsh, namely "Pointe-à-la-Bise". Locations (Station 1 to Station 5) correspond to a water transect of this natural freshwater system (Figure S3). For comparative purposes and to gain insight into the role of water composition, experiments were performed in synthetic lake water (SYNW) matching the ionic composition of Station 5 (Table S2), SYNW spiked with Suwannee River humic acid (SYNW-SRHA), and in culture medium of D. magna (CM). Standard humic acid isolated from the Suwannee River, SRHA, Georgia, was purchased from the International Humic Substances Society (St. Paul, MN, USA). The acute effects of NPLs on D. magna were determined by performing 48 -h immobilization tests. In parallel, the stability of the NPLs was characterized following their sizes (z-average hydrodynamic diameters) and zeta potentials ( $\zeta$-potentials) in natural freshwaters and different synthetic media.

\subsection{Water Sampling and Characterization of the Water Quality Parameters}

Five stations located at the transect of the natural reserve marsh "Pointe-à-la-Bise" connected to Lake Geneva (Figure S3) were sampled in February 2017. To this end, $1 \mathrm{~L}$ of marsh or lake water was collected in glass bottles pre-washed with acidified water at $50-\mathrm{cm}$ depth and at each sampling site. Back in the laboratory, water samples were filtered with $0.45-\mu \mathrm{m}$ pore size filters (Millipore) and stored in the dark at $4{ }^{\circ} \mathrm{C}$ before further use. Major anion and cation composition $\left(\mathrm{Na}^{+}, \mathrm{Mg}^{2+}, \mathrm{Ca}^{2+}, \mathrm{K}^{+}, \mathrm{Cl}^{-}, \mathrm{PO}_{4}{ }^{3-}, \mathrm{SO}_{4}{ }^{2-}\right.$, and $\mathrm{NO}_{3}{ }^{-}$) was measured in filtered water samples within two days after sampling with ion chromatography (ICS-3000, Thermo Fisher Scientific, Dionex, Switzerland) according to manufacturer's specifications. Calibration was performed with standards at four levels for each component (TraceCert single ion standards, Sigma-Aldrich Chemie GmbH, Buchs, Switzerland). In parallel, water samples were also collected for the determination of dissolved organic carbon (DOC) concentrations in $550^{\circ} \mathrm{C}$ burned glass bottles after filtration on $0.7 \mu \mathrm{m} \mathrm{GF} / \mathrm{F}$ filters (also previously pyrolyzed) and acidified with $\mathrm{HCl}$ at $2 \mathrm{M}$. The concentration of DOC was measured with a Shimadzu TOC analyzer (Shimadzu, Scientific Instruments, Kyoto, Japan). Calibration was performed with TOC standard solution at four levels (CertiPur, Merck, Darmstadt, Germany). Obtained results presenting the background water chemistry parameters to probe the stability and effects of the PS nanospheres are given in Table S2. Results demonstrated the existence of significant but limited gradients in the concentration of dissolved organic carbon, and for some ions such as $\mathrm{Ca}^{2+}, \mathrm{K}^{+}$, and $\mathrm{Cl}^{-}$, having decreasing concentrations from Station 1 (Pointe-à-la-Bise marsh) towards Station 5 (Lake Geneva). 


\subsection{Characterization of NPLs' Behavior in Natural Freshwaters and Synthetic Media}

Behavior of the NPLs of different primary sizes was characterized in terms of $\zeta$ potentials and z-average diameters in natural freshwater samples (Station 1 to 5) and synthetic media including ultra-pure water. Polystyrene suspensions of $50 \mathrm{mg} / \mathrm{L}$ were prepared and homogenized by using a magnetic stirrer $(250 \mathrm{rpm})$ (Labgene, Chatel-Saint-

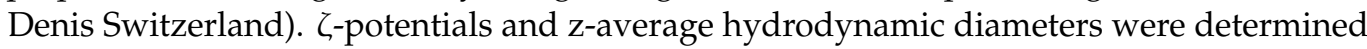
using a Zetasizer Nano (Malvern Instruments, Malvern, UK). This device was set up to give 3 consecutive measurements ( $10 \mathrm{sub}$-measures for each) at $20^{\circ} \mathrm{C}$ with $5 \mathrm{~s}$ pause between each measurement to stabilize the system. The behavior of the NPLs was first examined in ultra-pure water (reference media) at different pHs. Results indicate positive $\zeta$-potentials and stability regarding homoaggregation in a large $\mathrm{pH}$ range (Figure S4).

\subsection{Exposure of D. magna to NPLs in Natural and Synthetic Freshwater}

Acute toxicity effects of the NPLs of different primary sizes on crustacean Daphnia magna in natural freshwaters and synthetic media were examined by using a cyst-based DAPHTOXKIT test (Microbiotests Inc., Ghent, Belgium). The selected acute toxicity test follows the OECD guideline 202 for D. magna and offers a similar sensitivity to standard toxicity tests [33]. Briefly, D. magna was exposed to increasing concentrations of monodispersed amidine-functionalized polystyrene NPLs (Table S1) of different sizes ranging from 0.5 to $30 \mathrm{mg} / \mathrm{L}$ (and from 0.5 to $100 \mathrm{mg} / \mathrm{L}$ for 100-nm-sized NPLs) following standard operation procedures recommended by the provider. Three independent bioassays were conducted for replication. The test was validated if the immobilization of control groups did not exceed $10 \%$. Unexposed control groups were run for all experiment conditions. The concentrations of NPLs inducing immobilization in $50 \%$ of the exposed organisms $\left(\mathrm{EC}_{50}\right)$ were determined by using a four-parameter log-logistic model incorporated in SigmaPlot 12.5 (Systat Software GmbH, Erkrath, Germany).

\subsection{Data Treatment}

Data treatment was performed with SigmaPlot 12.5 (Systat Software GmbH, Erkrath, Germany). One-way ANOVA was used to compare the treatments with different NPLs and freshwaters. When the null hypothesis, which posits that there is no significant difference among the studied groups $(p<0.05)$, was rejected, the Tukey's Honest Significant Difference Test was applied to determine the individual significant difference from a set of means. Principal component analysis (PCA) was also used to identify relationships between obtained $\mathrm{EC}_{50}$ values, the NPs' characteristics in the exposure media, and water quality variables. The PCA was carried out with the package FactoMineR [34]. According to the instructions, data were centered and standardized because of the difference in the units of variables.

\section{Results and Discussion}

\subsection{Behavior of NPLs in Synthetic Media and Freshwaters}

Before the analysis of the behavior of NPLs in freshwaters, $\zeta$-potential values as well as z-average hydrodynamic diameters were determined in UPW, CM, SYNW, and SYNW-SRHA. All suspensions of NPLs in UPW, CM, and SYNW exhibited positive $\zeta$ potential values ranging between +20 and $+50 \mathrm{mV}$, with higher values being obtained in UPW (Figure 1A). The addition of $10 \mathrm{mg} / \mathrm{L}$ SRHA to SYNW (SYNW-SRHA) resulted in a significant decrease in $\zeta$-potentials. This observation indicates that SRHA, which is negatively charged, interacts significantly with the positive NPLs to form an eco-corona. The decrease in the $\zeta$-potentials, correlated with the size of NPLs, was found to be more important for larger NPLs. A charge reversal from positive to negative was even observed for the $100 \mathrm{~nm}$ NPLs. Such a decrease with the increase in NPLs' size can be explained by the decrease in the surface-to-volume ratio with size and therefore a decrease in the total number of surface charges. Therefore, due to better electrostatic repulsions, 20, 40, and $60 \mathrm{~nm}$ NPLs were found stable in UPW, CM, and SYNW with z-average diameters close to 
their primary sizes (Figure 1B). In synthetic water in the presence of SRHA, because of the formation of the eco-corona, significant surface charge neutralization, and a decrease in $\zeta$-potentials, NPLs were found unstable with aggregate sizes greater than $1000 \mathrm{~nm}$ in most cases. It should be noted that the $20 \mathrm{~nm}$ NPLs exhibited good stability (i.e., no significant aggregation) even in the presence of SRHA due to the limited decrease in their $\zeta$-potentials.
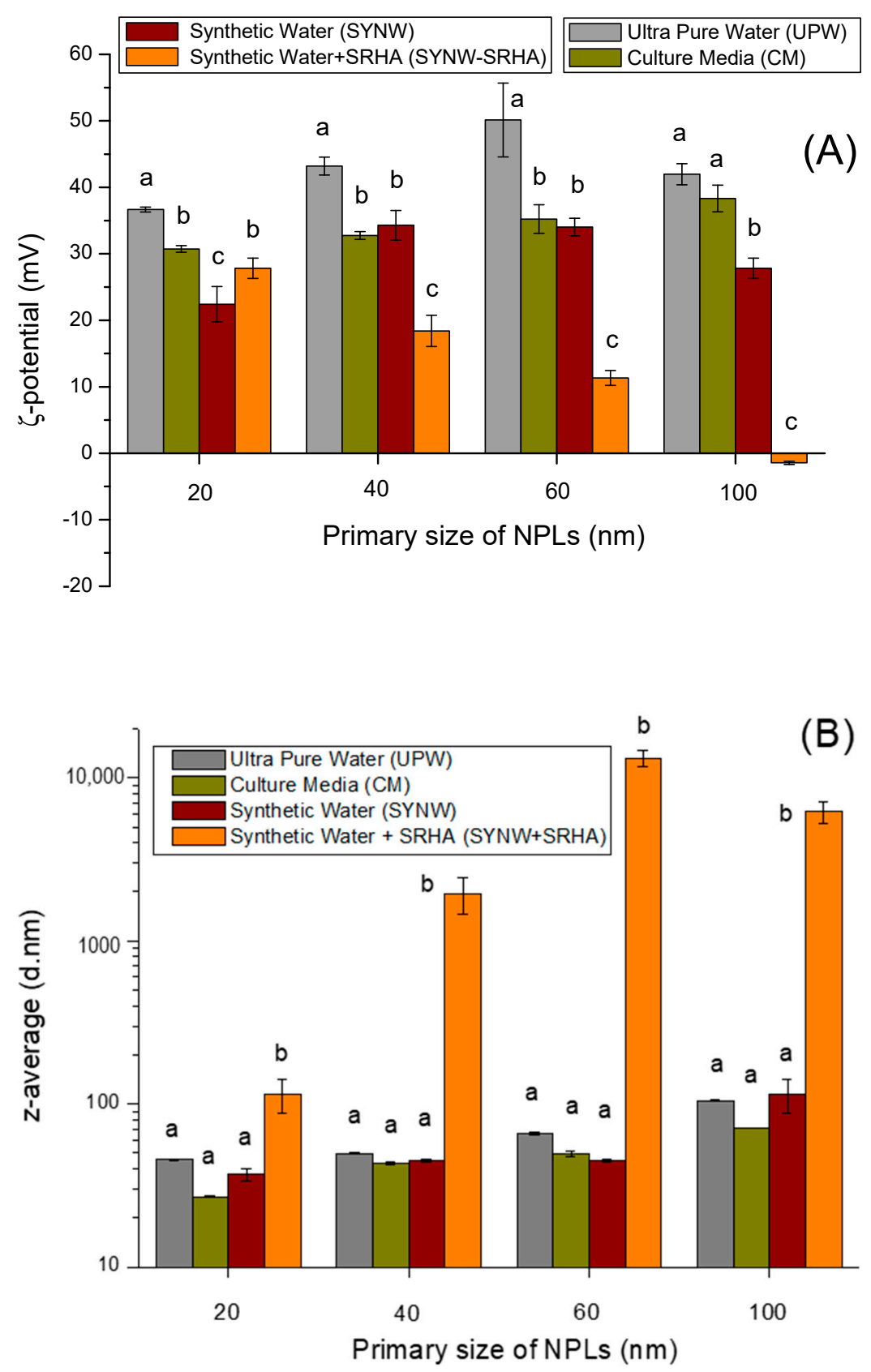

Figure 1. (A) $\zeta$-Potentials and (B) z-average hydrodynamic diameters of polystyrene nanoplastics (NPLs) at a concentration of $50 \mathrm{mg} / \mathrm{L}$ as a function of primary sizes in ultra-pure water (UPW), culture media (CM), synthetic water (SYNW), and synthetic water spiked with SRHA (SYNW-SRHA) at a concentration of $1 \mathrm{mg} / \mathrm{L}$. Letters $(\mathrm{a}, \mathrm{b}, \mathrm{c})$ indicate statistically significant difference between treatments (pairwise multiple comparison procedures-Tukey's test within each NPL size group, $p$-value $<0.05)$.

On the other hand, in natural freshwaters, $\zeta$-potentials decreased with the increase in NOM concentration (Figure 2A). The impact of NOM was more important for the 60 and $100 \mathrm{~nm}$ NPLs. Indeed, at a high NOM concentration (Station 1), a charge inversion was 
observed for the $100 \mathrm{~nm}$ NPLs and a significant decrease in the $\zeta$-potential to a value close to zero was obtained for the $60 \mathrm{~nm}$ NPLs.
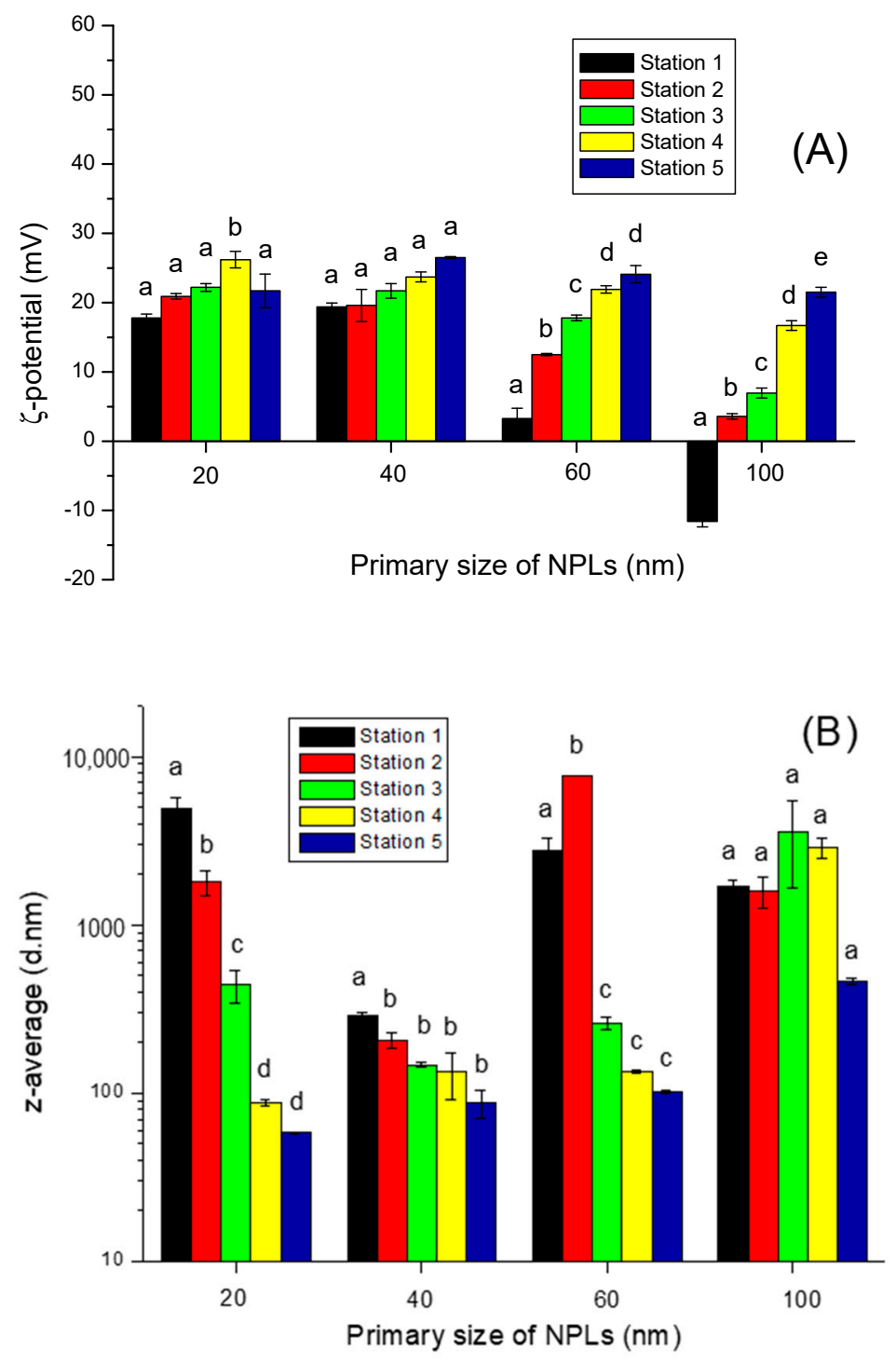

Figure 2. (A) $\zeta$-Potentials and (B) z-average diameters of polystyrene nanoplastics (NPLs) as a function of primary sizes in freshwaters at marsh-lake transect "Pointe-à-la-Bise". NPL concentration is equal to $50 \mathrm{mg} / \mathrm{L}$, and from Station 1 to Station 5, DOC concentration is equal to 1.681, 1.515, $1.326,1.116$, and $0.8795 \mathrm{mg} / \mathrm{L}$, respectively. Letters $(\mathrm{a}, \mathrm{b}, \mathrm{c}, \mathrm{d})$ indicate statistically significant difference between treatments (pairwise multiple comparison procedures-Tukey's test within each NPL size group, $p$-value $<0.05$ ).

Z-average diameter variations (Figure 2B) are found to be in good agreement with $\zeta$-potential values, i.e., decreasing the $\zeta$-potential value results in an increase in the $z$ average size and consequently the formation of NPL aggregates. The above results are found to be in good agreement with a previous study considering PS positively charged in bottled mineral and surface waters, in which the role of NOM and ionic composition was considered [35].

\subsection{Effect of NPLs of Different Sizes on Crustacean Daphnia magna}

The results of the acute toxicity tests on D. magna demonstrated that 20 and $40 \mathrm{~nm}$ NPLs exhibited a stronger negative effect as compared with 60 and $100 \mathrm{~nm}$ NPLs in both natural freshwaters and synthetic media. The percentages of D. magna immobilized over 
48-h exposure increased considerably with NPL concentrations (Figures 3 and 4) over the concentration range of 0.5 to $30 \mathrm{mg} / \mathrm{L}$ ( 0.5 to $100 \mathrm{mg} / \mathrm{L}$ for $100 \mathrm{~nm}$ NPs) for all the test media and NPL primary sizes.
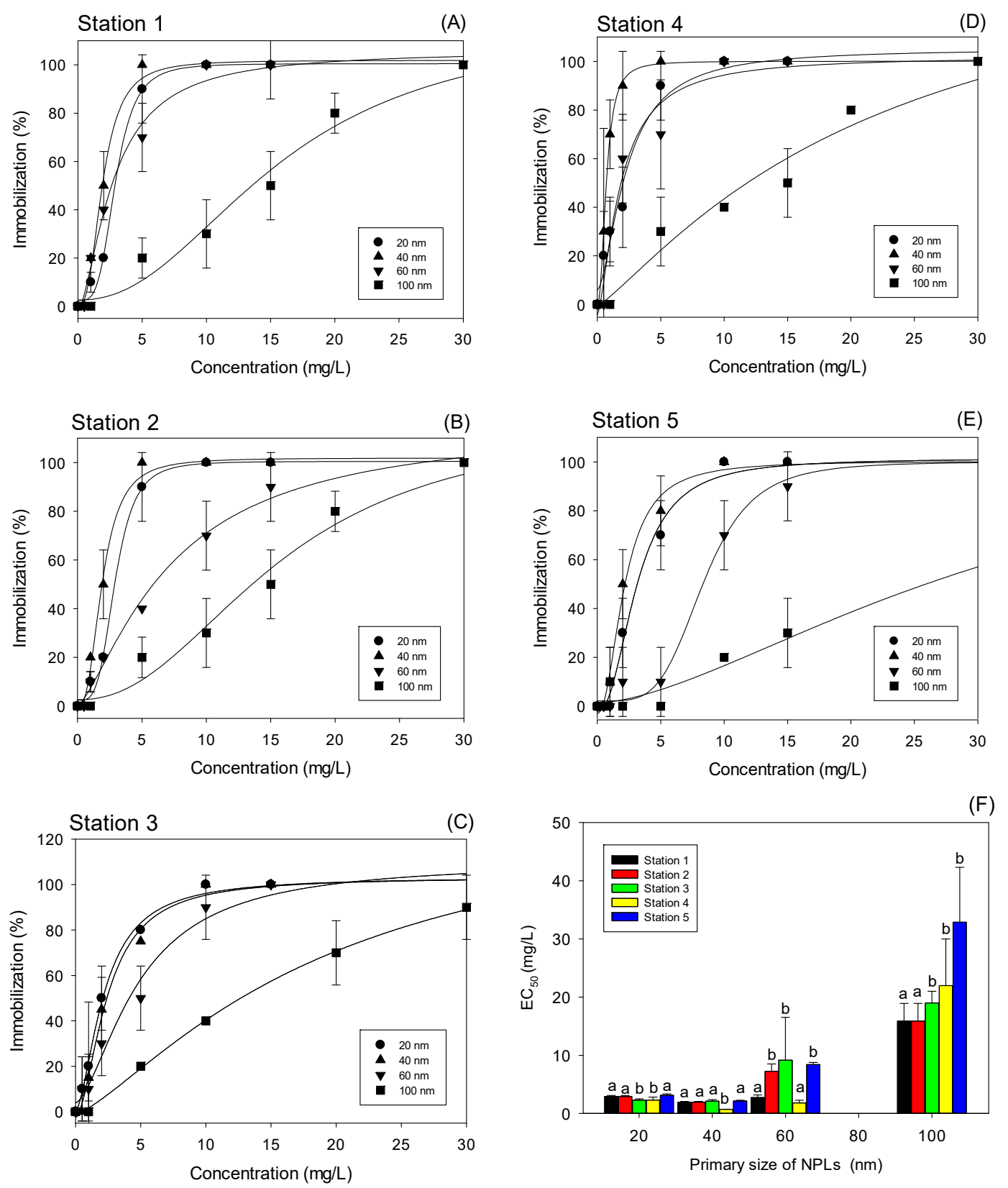

Figure 3. Dose-response (immobilization of D. magna) curves obtained during 48-h exposure in water from different sampling stations in marsh-lake transect (A-E). The lines represent the fit of experimental data with a four-parameter log-logistic model. Error bars represent the standard deviation when bigger than the symbol size, $N=3$. (F) Acute EC 50 values for D. magna, 48-h immobilization test, exposed to NPLs of different primary sizes obtained in natural water. Letters indicate statistically significant difference between treatments (pairwise multiple comparison procedures-Tukey's test within each NPL size group, $p$-value < 0.05). 

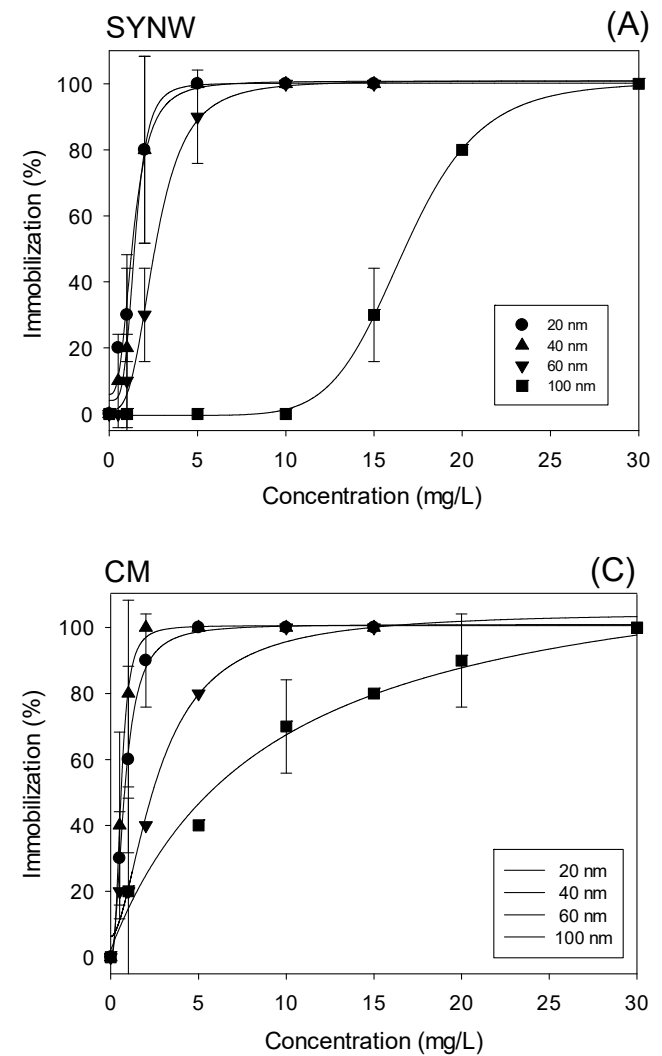

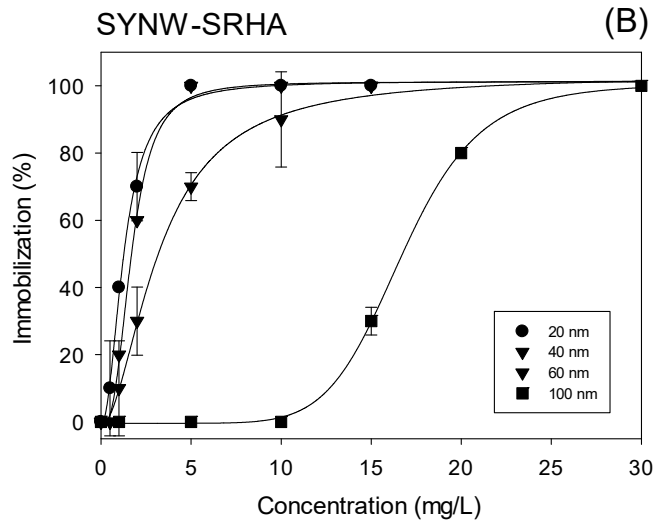

(D)

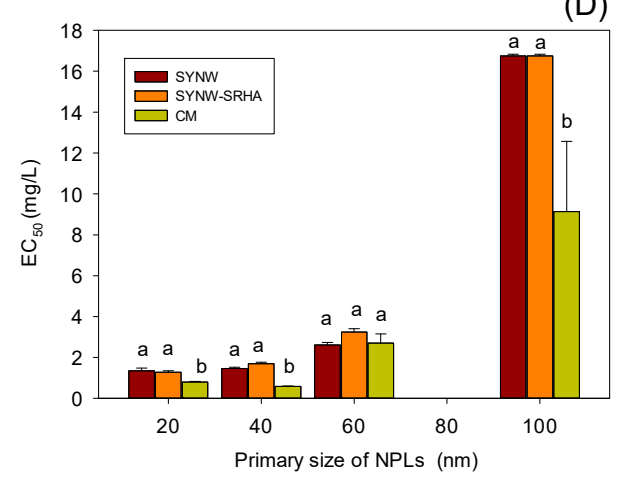

Figure 4. Immobilization of D. magna as a function of NPL concentration obtained in (A) synthetic medium, (B) synthetic medium with $1 \mathrm{mg} / \mathrm{L}$ SRHA added, and (C) D. magna culture medium. The lines represent the fit of experimental data with a four-parameter log-logistic model. Error bars represent the standard deviation when bigger than the symbol size, $\mathrm{N}=3$. (D) Acute $\mathrm{EC}_{50}$ values for D. magna, 48-h immobilization exposed to NPLs of different primary sizes obtained in synthetic media. The values are average \pm standard deviation for triplicate experiments $(\mathrm{N}=3)$. Letters indicate statistically significant difference between treatments (all pairwise multiple comparison procedures-Tukey's test within each group, $p$-value $<0.05)$.

However, for 20 and $40 \mathrm{~nm}$ NPLs, $\mathrm{EC}_{50}$ values were lower and the slopes of dose-response curves were steeper as compared with those for $100 \mathrm{~nm}$ NPLs, suggesting a stronger change in the percentage of organisms responding to lower-size NPLs. For example, in Station 1 (marsh water), $20 \mathrm{~nm}$ NPs were approximatively 5.4 times more toxic than $100 \mathrm{~nm}$ NPs. In Station 5 (lake water) and synthetic media, this difference reached 10-12 times. Comparable values of the acute $\mathrm{EC}_{50}$ (Figure 3 ) and toxicity slopes in the dose-response curves for the NPs of 20, 40, and 60-nm-size suggest that the primary size plays a prevailing role over the exposure medium's physicochemical parameters. By contrast, for $100 \mathrm{~nm}$ NPs, the $E_{50}$ increases and the toxicity slope decreases, as was found for the exposure in water from Station 1 to Station 5. This finding highlights the important role of the physicochemical parameters of the exposure medium in determining the behavior and toxicity of $100 \mathrm{~nm}$ NPLs towards D. magna. The results obtained here with 100-nm NPLs are in agreement with other studies showing that negatively-charged 200-nm-size PSCOOH induced about twice stronger immobilization of D. magna than non-functionalized PS [36]. However, they differed from the few existing studies and the idea that a higher positive surface charge would favor NPLs' bio-reactivity, since the $\zeta$-potential of $100 \mathrm{~nm}$ NPLs (Figure 2A) in water from Station 5 was significantly higher than that for water from Station 1, but the toxicity was lower. For example, $\mathrm{NH}_{2}$-functionalized polystyrene nanoparticles (presumably positively charged) induced more important detrimental effects in D. magna [23] as well as amidine-functionalized PS of 200-nm-size as compared with PSCOOH (negatively charged) [28]. 
In the SYNW, the $\mathrm{EC}_{50}$ values were about twice lower than those found in Station 5. The addition of $1 \mathrm{mg} / \mathrm{L}$ SRHA to NPL suspensions in the SYNW resulted in no influence on the negative effect of these particles on D. magna, as revealed by the comparable $\mathrm{EC}_{50}$ values in the CM (Figure 4). Under the same conditions, there was a significant reduction in the $\zeta$-potential of positively charged NPs with a primary size of 40,60, and $100 \mathrm{~nm}$, which in the presence of SRHA formed $\mu$ m-size agglomerates.

No significant difference in the acute toxicity was found, although there was a significant difference in the size and surface change in the synthetic water and synthetic water + SRHA. Maybe such a lack of difference can be explained by the fact that $D$. magna can ingest particles in large sizes up to $70 \mu \mathrm{m}$ [37]. Indeed, it was shown that D. magna can ingest microspheres of different sizes ranging from $20 \mathrm{~nm}$ to $1 \mu \mathrm{m}$ PS carboxylated microspheres, but $20 \mathrm{~nm}$ beads were retained to a greater degree within the gastrointestinal tract and they translocated into other compartments [37].

Significantly lower values of $\mathrm{EC}_{50}$ were found in D. magna culture medium for 20, 40 , and $100 \mathrm{~nm}$ NPLs in comparison with the other synthetic media. This difference was most pronounced for $100 \mathrm{~nm}$ NPs. For example, no effect of $100 \mathrm{~nm}$ NPs was observed in synthetic waters in the range $0.5-10 \mathrm{mg} / \mathrm{L}$, while $70 \%$ of $D$. magna was immobilized over $48 \mathrm{~h}$ in the culture media when exposed to $10 \mathrm{mg} / \mathrm{L}$ (Figure 4). The obtained results also imply that the tests in the culture media overestimated the effects in comparison to the synthetic lake water and natural lake waters.

Overall, the acute $\mathrm{EC}_{50}$ values obtained in the present study were in the range of 0.59 to $32.9 \mathrm{mg} / \mathrm{L}$ and depended on the primary size. Based on the results of the present study, amidine PS nanospheres of different sizes can be classified either as toxic (20 and $40 \mathrm{~nm})$ or as "harmful" (100 nm) for D. magna according to EU-Directive 93/67/EEC. The obtained values of $\mathrm{EC}_{50}$ were also within the reported large range for a variety of NPLs for 48-h immobilization for water flea D. magna [14,20-22,24-26,38]. However, direct comparison is not possible given the different exposure medium compositions, sizes, and surface functionalization of the particles as well as bioassays.

The possible link between the NPLs-induced acute effects in D. magna (48-h immobilization), their characteristics (primary size, $\zeta$-potential, and average size in the exposure medium), and the water quality parameters (DOC, used as a measure for NOM, major cation and anion composition) was further explored (Figure 5) via principal component analysis.

A significant positive correlation was found between the intensity of the induced effect and primary particle size, with smaller-size NPLs being more toxic (low EC 50 values). In natural freshwaters, the strongest impact of the $20 \mathrm{~nm}$ NPLs agreed not only with their smaller size and enhanced surface-to-volume ratio, but also with higher positive values of the $\zeta$-potential of $20 \mathrm{~nm}$ NPLs (Figures 1 and 2) as compared with $100 \mathrm{~nm}$ NPLs in the tested media. Indeed, the cationic surface would enable particles to interact easily with negatively charged cell membranes [31]. However, in synthetic media and Station 5, even if the $\zeta$-potential values were comparable for all tested NPLs, the toxicity of the 20-nm-size NPLs was much stronger. 


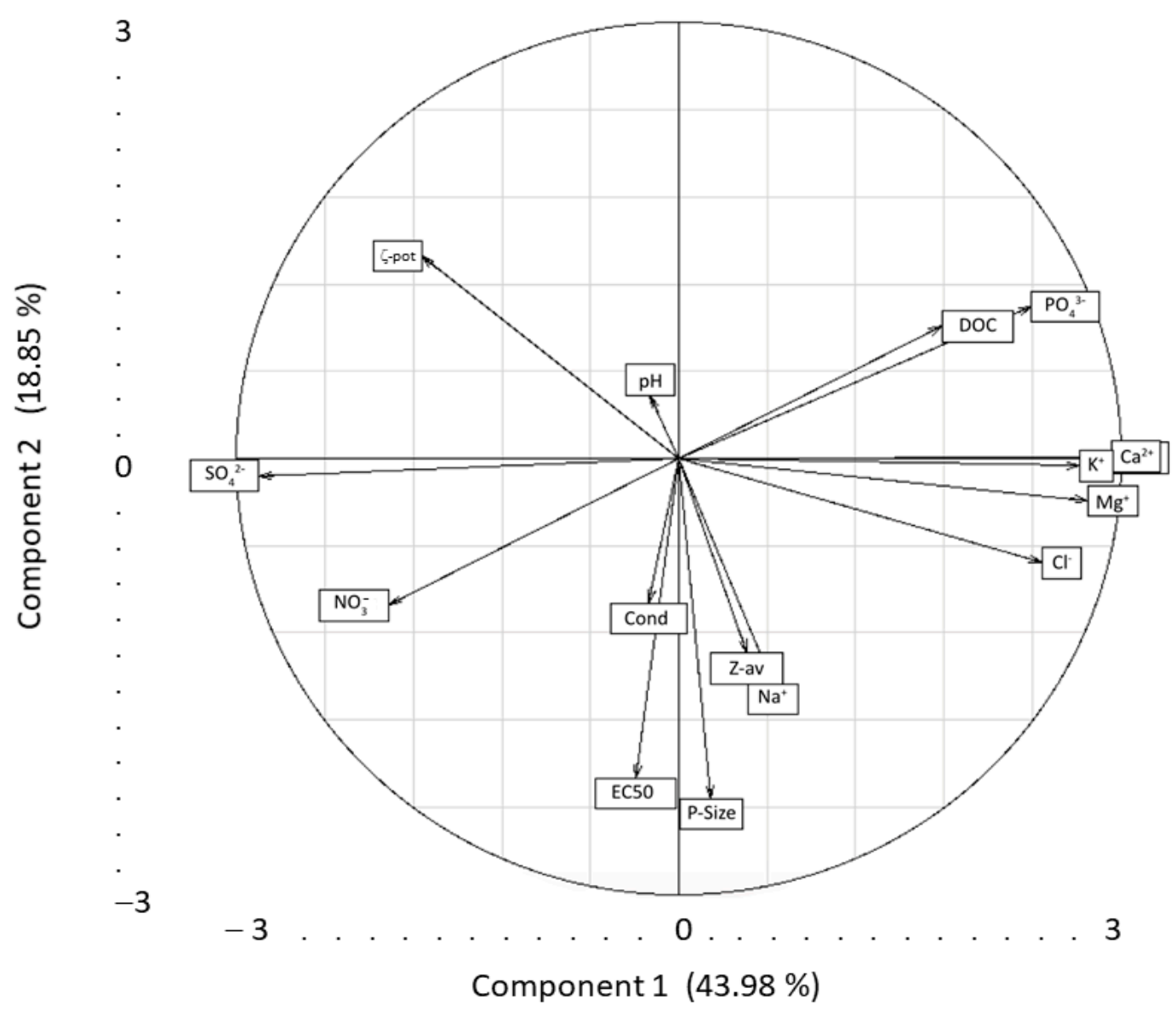

Figure 5. Principal component analysis (first two PCs) between $\mathrm{EC}_{50}$ obtained in 48-h immobilization test, $\mathrm{z}$-average size (Z-av), $\zeta$-potential ( $\zeta$-pot), primary size (P-Size) of NPLs and different physicochemical characteristics of the exposure media: DOC (dissolved organic carbon), $\mathrm{pH}$, conductivity (Cond), ionic composition, $\mathrm{Na}^{+}, \mathrm{K}^{+}, \mathrm{Ca}^{2+}, \mathrm{Cl}^{-}, \mathrm{NO}_{3}^{-}, \mathrm{SO}_{4}^{2-}, \mathrm{PO}_{4}^{3-}$.

\section{Conclusions}

The present study aimed to obtain further insight into the behavior and effect of NPLs of different sizes in freshwaters and different media. The results showed that no measurable aggregation of PS NPLs of different sizes in UPW, CM, and SYNW was observed, in agreement with positive values of $\zeta$-potentials greater than $+20 \mathrm{mV}$. In SYNWSRHA as well as in freshwaters, NOM eco-corona was found to have a significant effect on the NPLs' $\zeta$-potentials and a significant aggregation of PS NPLs was found in particular for the larger NPLs (60 and $100 \mathrm{~nm}$ ), showing that NOM has a stronger influence on the stability of larger NPLs. Smaller NPLs (20 and $40 \mathrm{~nm}$ ) exhibited better stability in both freshwaters and synthetic media. PS NPLs with sizes between 20 and $100 \mathrm{~nm}$ were toxic to D. magna. The acute toxicity strongly depended on the NPLs' primary size and the 20 and 40-nm-size amidine PS NPLs were found to be more toxic than larger ones in both natural and synthetic freshwaters. Water quality variables such as $\mathrm{pH}$, cation and anion composition, and DOC were of secondary importance. Overall, the results of the present study revealed the toxicity of NPLs of different sizes to crustaceans in natural lake water and different synthetic media and the importance of the primary size of NPLs in particle-crustacean interactions.

Supplementary Materials: The following are available online at https:/ /www.mdpi.com/article/10 .3390 / environments $8100101 /$ s1, Figure S1: Intensity particle size distribution measured in ultra-pure water by dynamic light scattering: (a) 20, (b) 40, (c) 60, and (d) $100 \mathrm{~nm}$ NPLs, Figure S2: SEM images and results of size image analysis of (a) 20 and (b) $100 \mathrm{~nm}$ NPLs, Figure S3: Lake Geneva map, location of the "Pointe-à-la-Bise" marsh and transect (right), Figure S4: ל-Potential and z- 
average hydrodynamic diameter $(\mathrm{nm})$ variations as a function of $\mathrm{pH}$ obtained in ultra-pure water, Table S1: Characteristics of 20, 40,60, and $100 \mathrm{~nm}$ polystyrene nanoplastics (NPLs) as provided by the manufacturer, Table S2: Ionic compositions and DOC of freshwaters sampled from Station 1 to Station 5 of transect Pointe-à-la-Bise.

Author Contributions: Conceptualization, A.P., S.S. and V.I.S.; methodology, A.P.; software, A.P., S.S. and V.I.S.; validation, A.P., S.S. and V.I.S.; writing-original draft preparation, A.P.; writing-review and editing, S.S. and V.I.S.; experiments, A.P.; supervision, S.S. and V.I.S. All authors have read and agreed to the published version of the manuscript.

Funding: This research received no external funding.

Institutional Review Board Statement: Not applicable.

Informed Consent Statement: Not applicable.

Acknowledgments: The authors acknowledge financial support received from the Commission des travaux de Master (MUSE), Agathe Martignier for her support during the SEM measurements, Emmanuel Castella for statistical analysis, and Lina Ramirez, Séverine Le Faucheur, Olena Oriekhova, and Arnaud Clavier for technical support.

Conflicts of Interest: The authors declare no conflict of interest.

\section{References}

1. Alimi, O.S.; Budarz, J.F.; Hernandez, L.M.; Tufenkji, N. Microplastics and nanoplastics in aquatic environments: Aggregation, deposition, and enhanced contaminant transport. Environ. Sci. Technol. 2018, 52, 1704-1724. [CrossRef]

2. Thompson, R.C.; Moore, C.J.; vom Saal, F.S.; Swan, S.H. Plastics, the environment and human health: Current consensus and future trends. Philos. Trans. R. Soc. B Biol. Sci. 2009, 364, 2153-2166. [CrossRef]

3. Zhang, B.; Chao, J.Y.; Chen, L.; Liu, L.C.; Yang, X.; Wang, Q. Research progress of nanoplastics in freshwater. Sci. Total Environ. 2021, 757, 143971. [CrossRef]

4. Kukkola, A.; Krause, S.; Lynch, I.; Sambrook Smith, G.H.; Nel, H. Nano and microplastic interactions with freshwater biotaCurrent knowledge, challenges and future solutions. Environ. Int. 2021, 152, 106504. [CrossRef] [PubMed]

5. Gaylarde, C.C.; Baptista Neto, J.A.; da Fonseca, E.M. Nanoplastics in aquatic systems-Are they more hazardous than microplastics? Environ. Pollut. 2021, 272, 115950. [CrossRef] [PubMed]

6. Galloway, T.S.; Cole, M.; Lewis, C. Interactions of microplastic debris throughout the marine ecosystem. Nat. Ecol. Evol. 2017, 1, 0116. [CrossRef]

7. Galloway, T.S.; Lewis, C.N. Marine microplastics spell big problems for future generations. Proc. Natl. Acad. Sci. USA 2016, 113, 2331. [CrossRef] [PubMed]

8. Eerkes-Medrano, D.; Thompson, R.C.; Aldridge, D.C. Microplastics in freshwater systems: A review of the emerging threats, identification of knowledge gaps and prioritisation of research needs. Water Res. 2015, 75, 63-82. [CrossRef]

9. Wagner, M.; Scherer, C.; Alvarez-Muñoz, D.; Brennholt, N.; Bourrain, X.; Buchinger, S.; Fries, E.; Grosbois, C.; Klasmeier, J.; Marti, T.; et al. Microplastics in freshwater ecosystems: What we know and what we need to know. Environ. Sci. Eur. 2014, 26, 12. [CrossRef]

10. Oriekhova, O.; Stoll, S. Heteroaggregation of nanoplastic particles in the presence of inorganic colloids and natural organic matter. Environ. Sci. Nano 2018, 5, 792-799. [CrossRef]

11. Junaid, M.; Wang, J. Interaction of nanoplastics with extracellular polymeric substances (eps) in the aquatic environment: A special reference to eco-corona formation and associated impacts. Water Res. 2021, 201, 117319. [CrossRef] [PubMed]

12. Grassi, G.; Gabellieri, E.; Cioni, P.; Paccagnini, E.; Faleri, C.; Lupetti, P.; Corsi, I.; Morelli, E. Interplay between extracellular polymeric substances (eps) from a marine diatom and model nanoplastic through eco-corona formation. Sci. Total Environ. 2020, 725, 138457. [CrossRef] [PubMed]

13. Buffle, J.; Wilkinson, K.J.; Stoll, S.; Filella, M.; Zhang, J. A generalized description of aquatic colloidal interactions: The threecolloidal component approach. Environ. Sci. Technol. 1998, 32, 2887-2899. [CrossRef]

14. Fadare, O.O.; Wan, B.; Liu, K.; Yang, Y.; Zhao, L.; Guo, L.-H. Eco-corona vs. protein corona: Effects of humic substances on corona formation and nanoplastic particle toxicity in daphnia magna. Environ. Sci. Technol. 2020, 54, 8001-8009. [CrossRef] [PubMed]

15. Pulido-Reyes, G.; Leganes, F.; Fernández-Piñas, F.; Rosal, R. Bio-nano interface and environment: A critical review. Environ. Toxicol. Chem. 2017, 36, 3181-3193. [CrossRef]

16. Chae, Y.; An, Y.J. Effects of micro- and nanoplastics on aquatic ecosystems: Current research trends and perspectives. Mar. Pollut. Bull. 2017, 124, 624-632. [CrossRef]

17. Jacob, H.; Besson, M.; Swarzenski, P.W.; Lecchini, D.; Metian, M. Effects of virgin micro- and nanoplastics on fish: Trends, meta-analysis, and perspectives. Environ. Sci. Technol. 2020, 54, 4733-4745. [CrossRef] 
18. Thomas, P.J.; Perono, G.; Tommasi, F.; Pagano, G.; Oral, R.; Buric, P.; Kovacic, I.; Toscanesi, M.; Trifuoggi, M.; Lyons, D.M. Resolving the effects of environmental micro- and nanoplastics exposure in biota: A knowledge gap analysis. Sci. Total Environ. 2021, 780, 11. [CrossRef]

19. Besseling, E.; Wang, B.; Lürling, M.; Koelmans, A.A. Nanoplastic affects growth of S. obliquus and reproduction of D. magna. Environ. Sci. Technol. 2014, 48, 12336-12343. [CrossRef]

20. Booth, A.M.; Hansen, B.H.; Frenzel, M.; Johnsen, H.; Altin, D. Uptake and toxicity of methylmethacrylate-based nanoplastic particles in aquatic organisms. Environ. Toxicol. Chem. 2016, 35, 1641-1649. [CrossRef]

21. Casado, M.P.; Macken, A.; Byrne, H.J. Ecotoxicological assessment of silica and polystyrene nanoparticles assessed by a multitrophic test battery. Environ. Int. 2013, 51, 97-105. [CrossRef] [PubMed]

22. Naha, P.C.; Casey, A.; Tenuta, T.; Lynch, I.; Dawson, K.A.; Byrne, H.J.; Davoren, M. Preparation, characterization of nipam and nipam/bam copolymer nanoparticles and their acute toxicity testing using an aquatic test battery. Aquat. Toxicol. 2009, 92, 146-154. [CrossRef] [PubMed]

23. Nasser, F.; Lynch, I. Secreted protein eco-corona mediates uptake and impacts of polystyrene nanoparticles on daphnia magna. J. Proteom. 2016, 137, 45-51. [CrossRef] [PubMed]

24. Rist, S.; Baun, A.; Hartmann, N.B. Ingestion of micro- and nanoplastics in daphnia magna-Quantification of body burdens and assessment of feeding rates and reproduction. Environ. Pollut. 2017, 228, 398-407. [CrossRef] [PubMed]

25. Lin, W.; Jiang, R.; Hu, S.; Xiao, X.; Wu, J.; Wei, S.; Xiong, Y.; Ouyang, G. Investigating the toxicities of different functionalized polystyrene nanoplastics on daphnia magna. Ecotoxicol. Environ. Saf. 2019, 180, 509-516. [CrossRef]

26. Vaz, V.P.; Nogueira, D.J.; Vicentini, D.S.; Matias, W.G. Can the sonication of polystyrene nanoparticles alter the acute toxicity and swimming behavior results for daphnia magna? Environ. Sci. Pollut. Res. 2021, 28, 14192-14198. [CrossRef]

27. Liu, Z.Q.; Li, Y.M.; Perez, E.; Jiang, Q.C.; Chen, Q.; Jiao, Y.; Huang, Y.Y.; Yang, Y.; Zhao, Y.L. Polystyrene nanoplastic induces oxidative stress, immune defense, and glycometabolism change in daphnia pulex: Application of transcriptome profiling in risk assessment of nanoplastics. J. Hazard. Mater. 2021, 402, 123778. [CrossRef]

28. Saavedra, J.; Stoll, S.; Slaveykova, V.I. Influence of nanoplastic surface charge on eco-corona formation, aggregation and toxicity to freshwater zooplankton. Environ. Pollut. 2019, 252, 715-722. [CrossRef]

29. Wu, J.; Jiang, R.; Lin, W.; Ouyang, G. Effect of salinity and humic acid on the aggregation and toxicity of polystyrene nanoplastics with different functional groups and charges. Environ. Pollut. 2019, 245, 836-843. [CrossRef]

30. Thompson, R.C.; Swan, S.H.; Moore, C.J.; vom Saal, F.S. Our plastic age. Philos. Trans. R. Soc. B Biol. Sci. 2009, $364,1973-1976$. [CrossRef]

31. Nel, A.; Xia, T.; Mädler, L.; Li, N. Toxic potential of materials at the nanolevel. Science 2006, 311, 622-627. [CrossRef]

32. Kwon, B.G.; Koizumi, K.; Chung, S.-Y.; Kodera, Y.; Kim, J.-O.; Saido, K. Global styrene oligomers monitoring as new chemical contamination from polystyrene plastic marine pollution. J. Hazard. Mater. 2015, 300, 359-367. [CrossRef]

33. Persoone, G.; Janssen, C.; De Coen, W. Cyst-based toxicity tests x: Comparison of the sensitivity of the acute daphnia magna test and two crustacean microbiotests for chemicals and wastes. Chemosphere 1994, 29, 2701-2710. [CrossRef]

34. Lê, S.; Josse, J.; Husson, F. Factominer: An r package for multivariate analysis. J. Stat. Softw. 2008, 25, 18. [CrossRef]

35. Ramirez Arenas, L.; Ramseier Gentile, S.; Zimmermann, S.; Stoll, S. Coagulation of $\mathrm{TiO}_{2}, \mathrm{CeO}_{2}$ nanoparticles, and polystyrene nanoplastics in bottled mineral and surface waters. Effect of water properties, coagulant type, and dosage. Water Environ. Res. 2020, 92, 1184-1194. [CrossRef]

36. Kim, D.; Chae, Y.; An, Y.J. Mixture toxicity of nickel and microplastics with different functional groups on daphnia magna. Environ. Sci. Technol. 2017, 51, 12852-12858. [CrossRef] [PubMed]

37. Rosenkranz, P.; Chaudhry, Q.; Stone, V.; Fernandes, T.F. A comparison of nanoparticle and fine particle uptake by daphnia magna. Environ. Toxicol. Chem. 2009, 28, 2142-2149. [CrossRef]

38. Rehse, S.; Kloas, W.; Zarfl, C. Short-term exposure with high concentrations of pristine microplastic particles leads to immobilisation of daphnia magna. Chemosphere 2016, 153, 91-99. [CrossRef] [PubMed] 